\title{
Characteristic Analysis of Peak Load in Electricity on Large Scale Hotels Considering the Energy Efficiency
}

\author{
Ji-Hye, Ryu ${ }^{1}$, Won-Hwa, Hong $^{2} *$ and Youn-Kyu, Seo $^{3}$ \\ ${ }^{1}$ Ph.D Student, School of Architectural, Civil, Environmental and Energy Eng. \\ Kyungpook National University, Daegu, Korea \\ ${ }^{2}$ Professor, School of Architectural, Civil, Environmental and Energy Eng. \\ Kyungpook National University, Daegu, Korea \\ ${ }^{3}$ Ph.D Student, School of Architectural, Civil, Environmental and Energy Eng. \\ Kyungpook National University, Daegu, Korea \\ ${ }^{1}$ ryou0407@knu.ac.kr, ${ }^{2} h o n g w h @ k n u . a c . k r,{ }^{3}$ s0913@knu.ac.kr \\ Abstract
}

\begin{abstract}
The demand for electricity in Korea has been on the rise due to economic growth, changes in weather conditions, and the widespread use of electri devices The excessive demand for electricity that used to occur only during the summer now occurs during the winter as well. As a result, it is now necessary to manage the electricity load bfbuildings in a stable way.

The study is intended to analyze the posstbility of reducing the entire electricity load and electricity peak load through an improvement in the energy efficiency of hotels buildings that are typical high energy consuming buildings, and topropose a plan to reduce electricity peak load through a decrease in the entire plectricity load. Using the electricity load data of the hotel buildings, the properties of electricity toad and the correlations between building energy efficiency rating and electrity peak lodd were analyzed. In so doing, this study can contribute not only to reduing the peak load of buildings, but also leveling off energy supply and load through a reduction in the nation largest electricity demand.
\end{abstract}

Keywords: Electricity, Energy Effictency, Energy Consumption, Hotel Building Energy, Correlation factor analysis

\section{Introduction}

\subsection{Background and Purpose}

The demand for electricity in Korea has been on the rise due to economic growth, changes in weatherconditions, and the widespread use of electric devices. The excessive demand for electricity that used to occur only during the summer now occurs during the winter as well. As a result, it is now necessary to manage the electricity load of buildings in a stable way. Investigating electricity load is a prerequisite for technically and economically evaluating the energy management of buildings and finding alternatives. From the perspective of national energy and security, it is also necessary to manage and predict the electricity peak load of buildings that use a large amount of energy. The energy efficiency of buildings should be examined from the standpoint of the buildings' energy consumption.

In this study, the properties of electricity peak load were analyzed according to building energy efficiency ratings. The study was focused on typical large-scale hotels that have high energy consumption per unit area and cause a massive amount of load. Using the electricity 
load data of the hotel buildings, the properties of electricity load and the correlations between building energy efficiency rating and electricity peak load were analyzed.

In so doing, this study can contribute not only to reducing the peak load of buildings, but also leveling off energy supply and load through a reduction in the nation's largest electricity demand.

This researcher visited large-scale hotels that are of considerable size and are located in Daegu, Korea, and met with the people in charge of managing the hotel facilities in order to learn about the facilities' electricity consumption by hour. This researcher examined the raw data regarding the buildings' energy efficiency rating and then analyzed the properties of electricity peak load accordingly.

\subsection{Literature}

A prerequisite for analyzing the energy efficiency of buildings with high energy consumption is to analyze energy consumption and patterns. Therefore, researchers who recognized the importance of this field have conducted basic studies to investigate the properties of energy consumption.

Although research on the energy consumption of domestic hotels and large buildings is currently being performed, there is a lack of thorough research on energy efficiency, consumption patterns, and consumption factors. This chapter describes studies on hotels and their electricity load.

Jae-hee Han proposed a technique to reduce electricity Joad during peak times by regulating household appliances. In addition, he employed the users' environmental factors in controlling load, and thereby gave degrees of freedom to users in terms of functional implementation [2].

Nabeel I. A. Tawalbeh used the houtly electricity data of urban substations to create daily electricity load and monthly electricity peak profiles [9].

Patricia R.S. Jota et al. recognized that load pattern synthesis is one of the important phases in a load management program, and they proposed a methodology of load pattern synthesis. They suggested that it as possible to predict load and peak demand through clustering and time-series data analysis [10].

Byeong-hun Sohn et al. investigated yearly electricity and city gas consumption of largescale hotels, and thereby identfied their electricity, oil, and gas consumption patterns. They also estimated the monthly energy consumption unit [13].

William Chung et al. analyzed the energy efficiency of personal office buildings in Hong Kong by using standardized data. They classified the data into five types of user groups, identified the energy-use intensity (EUI) $\left(\mathrm{MJ} / \mathrm{m}^{2}\right)$, and analyzed the energy efficiency of each group via regression model analysis [14].

\section{General Energy Consumption of Hotels}

\subsection{Energy Consumption of Hotels}

Given their role in accommodating people who travel for business, large hotel buildings serve as a place used by many people. Therefore, they have increasing energy consumption and energy demand.

As the electricity demand of cooling and heating systems, interior decorative devices, and lighting services in hotels has increased, there has been a steady increase in consumption of electricity-centered network energy. In addition, the advancement of information and office automation has led to an increase in electrical devices and facilities. As a result, hotels have 
become larger, and their energy use has been increasing rapidly. [12] Large hotel buildings are comprised of guest rooms for lodging, business facilities for administration, and subsidiary facilities such as banquet halls, conference rooms, amusement facilities, and restaurants.

Therefore, their energy demand is variable and their simultaneous energy load rises rapidly, leading to an increase in electricity consumption. It is necessary, therefore, to find a way to manage electricity efficiently.

A prerequisite for efficient energy consumption in large hotel buildings is to understand their energy consumption. An examination of the energy consumption of hotel buildings by energy source shows that electricity accounts for $58.93 \%$, city gas for $39.89 \%$, and oil for $3.1 \%$. Figure 1 illustrates the purposes of electricity consumption that make up the highest percentage of energy sources consumed in hotel buildings. Facility maintenance accounts for about $38.83 \%$, lighting for about $26.03 \%$, and cooling for about $17.04 \%$.

In addition, electricity is consumed for heating and office devices, but not for water heating. A total of $25 \%$ of all the electricity in hotels is consumed for cooling and heating. Therefore, due to seasonal climate changes, high consumption occûrs duing the summertime and wintertime, while comparatively low consumption occurs in the other seasons.

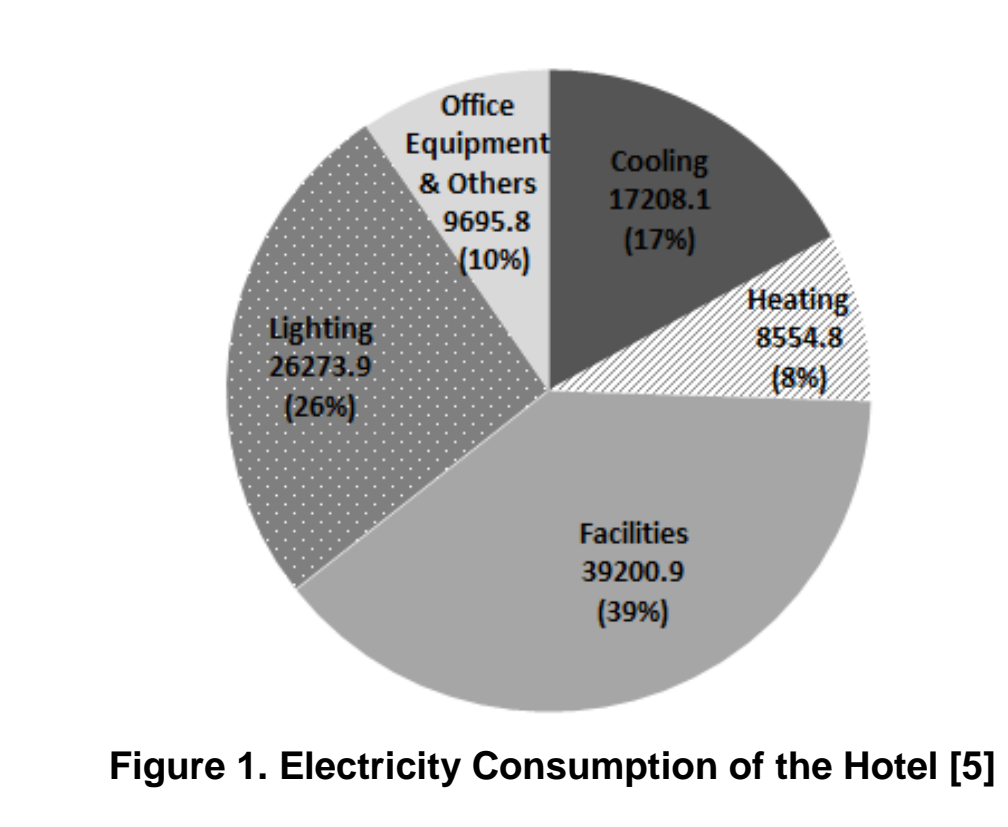

\subsection{Method of Estimating the Energy Efficiency Rating of Hotels}

From the standpoint of national energy security, it is necessary to investigate the properties of electricity peak load according to building energy efficiency ratings in order to manage the electricity peak load of large hotels that have high energy consumption per unit area. Management of electricity demand on the basis of building energy efficiency provides a great dea of economic and environmental advantages. Further, it can become an alternative to preventing excessive electricity demand from occurring during a certain period of the summer and winter. In this regard, when considering energy efficiency, it is necessary to thoroughly analyze the properties of electricity peak load of large hotels. Therefore, in this study the domestic building energy efficiency rating system was applied to hotels. The domestic building energy efficiency rating system was established by the government as a way to expand the construction of buildings with high energy performance and to manage building energy efficiently.[1] In accordance with the enforcement of the Construction Support Act for 
Table 2. Super Grade Hotel Status in Daegu, Korea [12]

\begin{tabular}{cccc}
\hline Grade & Super Deluxe & Deluxe & Total \\
\hline The Number & 3 & 6 & 9 \\
\hline
\end{tabular}

Table 3. Collection Status

\begin{tabular}{cccc}
\hline & Total Samples & Collection Samples & Not Collection Samples \\
\hline Hotels & 9 & 6 & 3 \\
\hline
\end{tabular}

\subsection{Analysis of Electricity Load}

Figure 2 illustrates the annual electricity load per unit area on the basis of the daily electricity load of each hotel. The annual electricity load per unit area showed a high demand in the winter, a decrease during the intermediate season, and a gradual increase in the summer. It is considered that the electricity load of hotels is related to the outdoor temperature. The load curve shows that a use pattern is repeated in the unit of a certain period. In other words, repeatedly, electricity load increases with a lapse of time within a certain time, and then it decreases. The repetition appears in the weekly unit, and the load patterns are similar, but electricity load varies depending on the season.

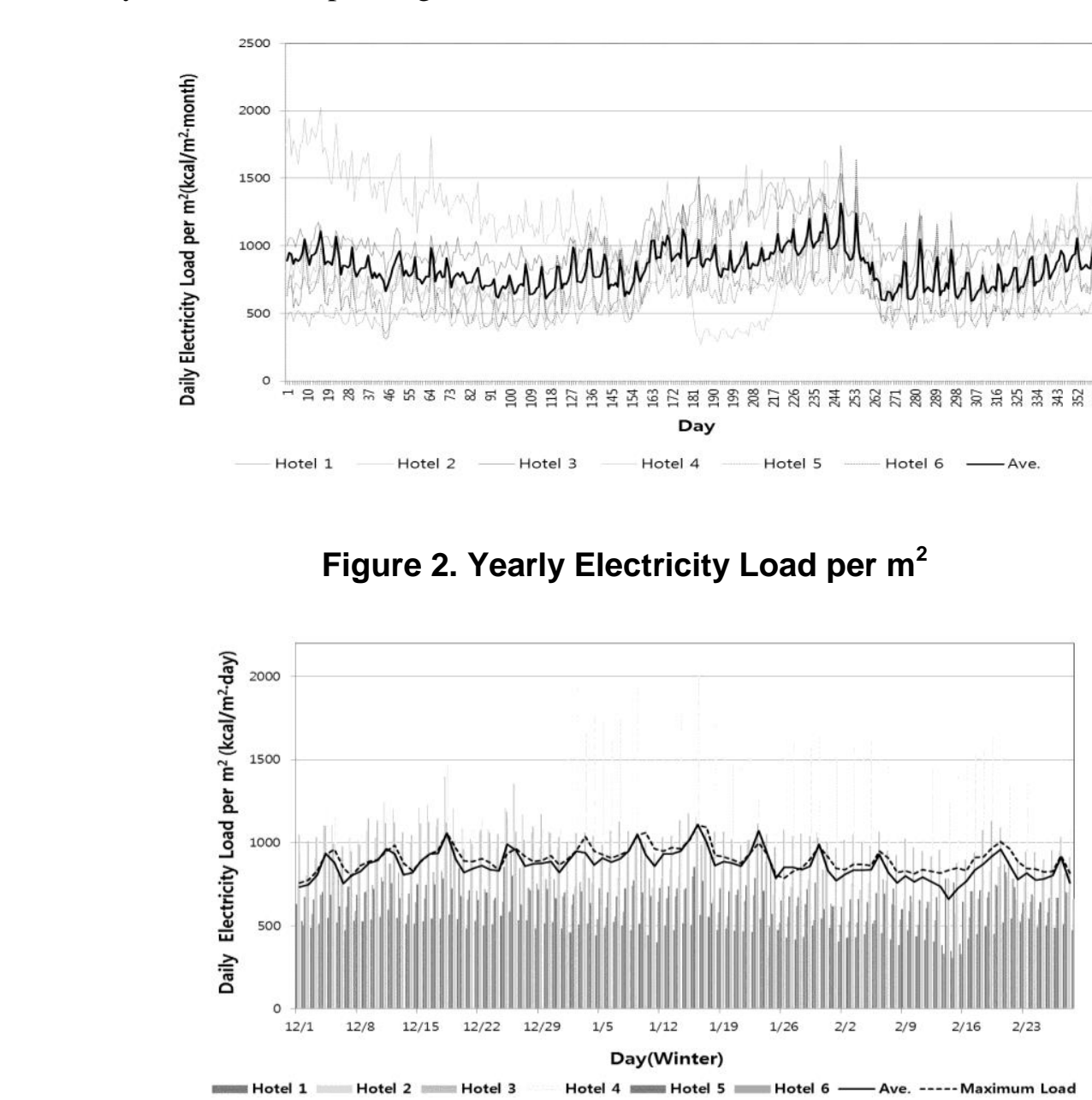

Figure 3. Winter Daily Electricity Load per $\mathbf{m}^{2}$ 


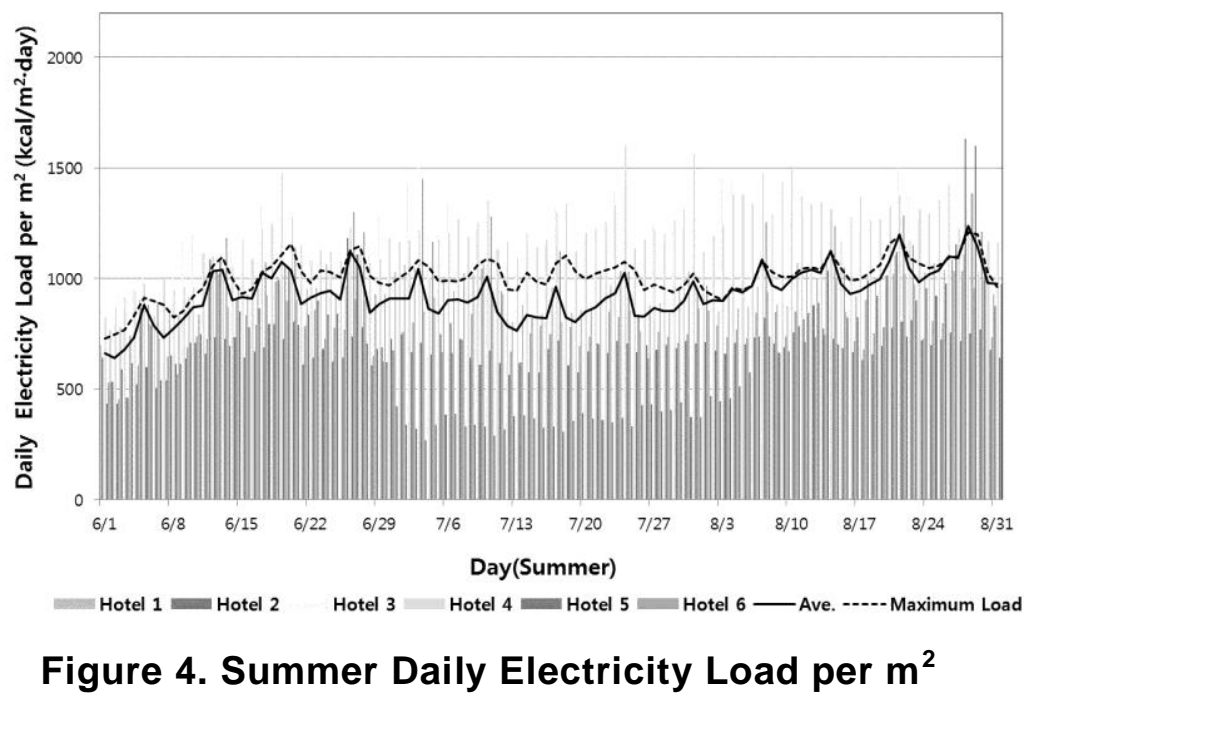

Figures 3 and 4 illustrate each daily electricity load per unit area of the summer and winter during which the annual maximum electricity load appears. A similar pattern of electricity load is repeated in the weekly unit. Based on the unit pattern electricity load increased from Monday to Friday, reached the peak on the weekend, and went back to being relatively low as the week started again. It is considered that this result was influenced by the number of visitors and guests who used hotels for weddings, banquets subsidiary facilities, and lodging.

The one day that displayed a different pattern was New Year's Day. The unique characteristics of the Korean national holiday appeared to cause a decrease in the electricity demands of hotels. A comparison of each daily eiectricity load per unit area during the winter and summer shows that electricity load is higher in the summer than the winter. The load rate was calculated by dividing the daily average electricity load by the daily maximum electricity load. The daily load ate in the winter was about $4.09 \%$, whereas in the summer it was up to $8.42 \%$. Therefore, it is concluded that the electricity peak occurrence frequency and electricity peak demand are much higher in the summer, when the difference between the average electricity load and the maximum electricity load is relatively large.

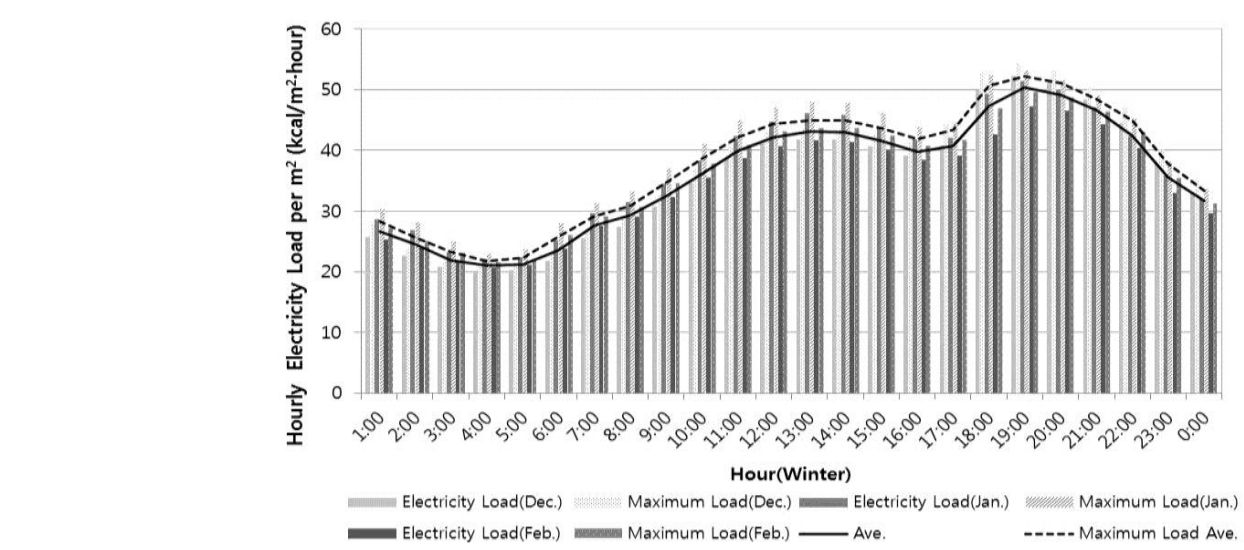

Figure 5. Winter Hourly Electricity Load per $\mathbf{m}^{2}$ 


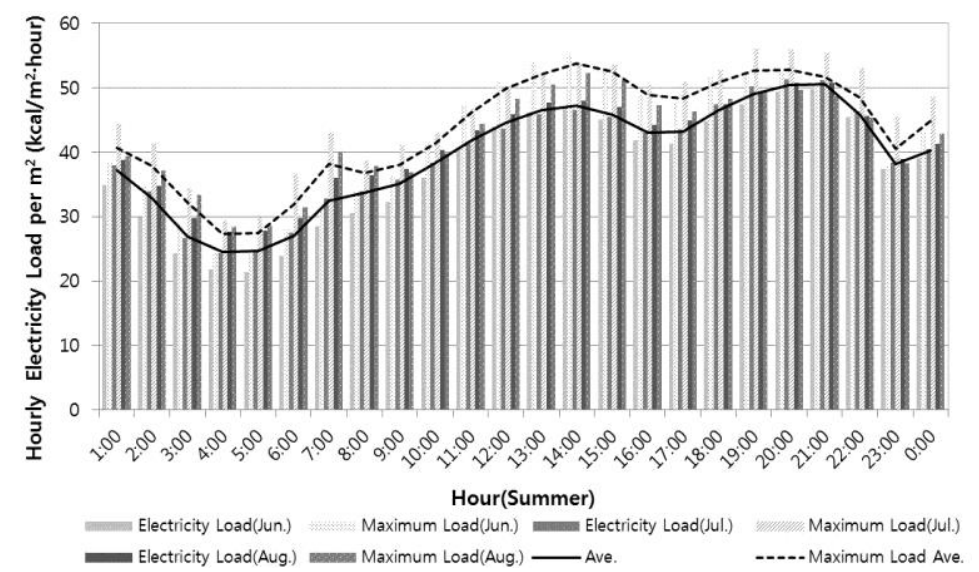

Figure 6. Summer Hourly Electricity Load per $\mathbf{m}^{2}$

In this study, an analysis was performed on the hourly electricity loac in the summer and winter, which have maximum peak demand according to the maximum electricity load occurrence. Given the hourly electricity load per mit area in the winter, electricity load increased until 13:00, and maximum electricity load occurred at $\$ 00 \mathrm{p} m$. After that, the load decreased gradually, and minimum electricity load occurred at 4.00 a.m. In the summer, maximum electricity load occurred at 2:00 $\mathrm{pm}$. and 9:00 $\mathrm{p}$. m. Also during that season, the nighttime electricity load was quite apparent due to the tropical conditions. Even at 7:00 a.m. when hotel guests started their daily activity a small peak1 oad occurred. This seems to be the result of HAVC system operation, in which the heat that was stored in the buildings at night is removed. The pattern difference between winter and summer also appears in the difference between maximum electricity load and average electricity load. The overall electricity load is higher in the summer than in the winter. At $6: 00$ p.m., when the maximum load rate occurred in the winter, the difference between average electricity load and maximum electricity load was about $3.29 \mathrm{kCal} / \mathrm{m}^{2}$ per hour. At 3:00 p.m., when the maximum load rate occurred in the summer, the difference was $6.67 \mathrm{kCal} / \mathrm{m}^{2}$ per hour. Such a difference varies depending on the system used, the needs of the guests, weather conditions, and unexpected excessive electricity demand. The efore, it is conctuded that the electricity peak demand is higher in the summer than in the winter

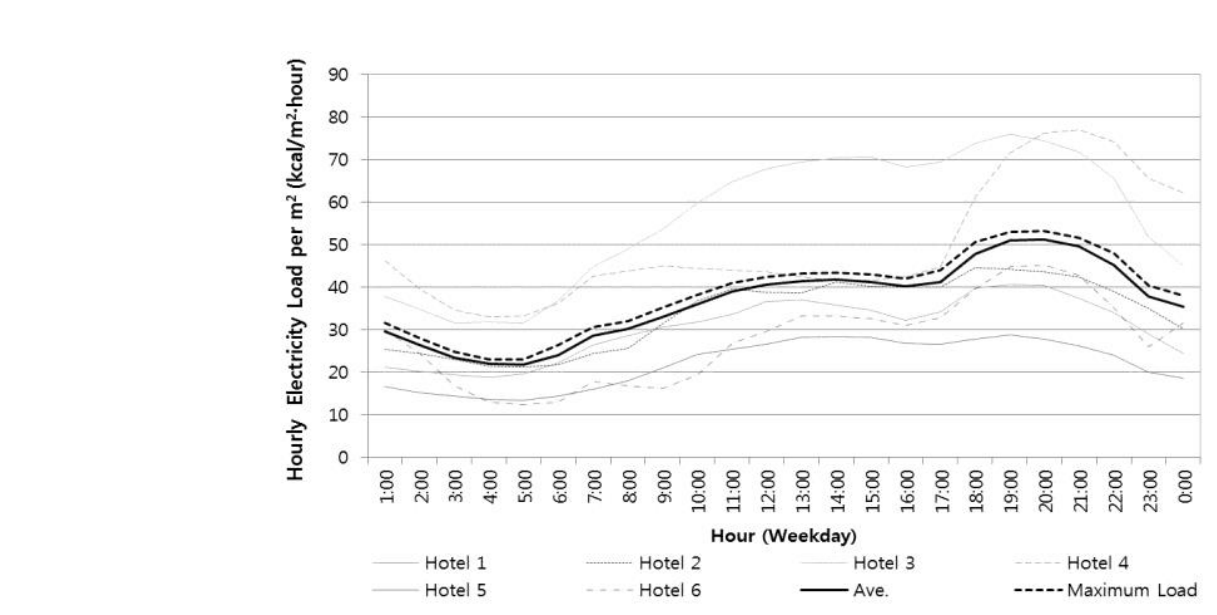

Figure 7. Weekday Hourly Electricity Load per $\mathbf{m}^{2}$ 


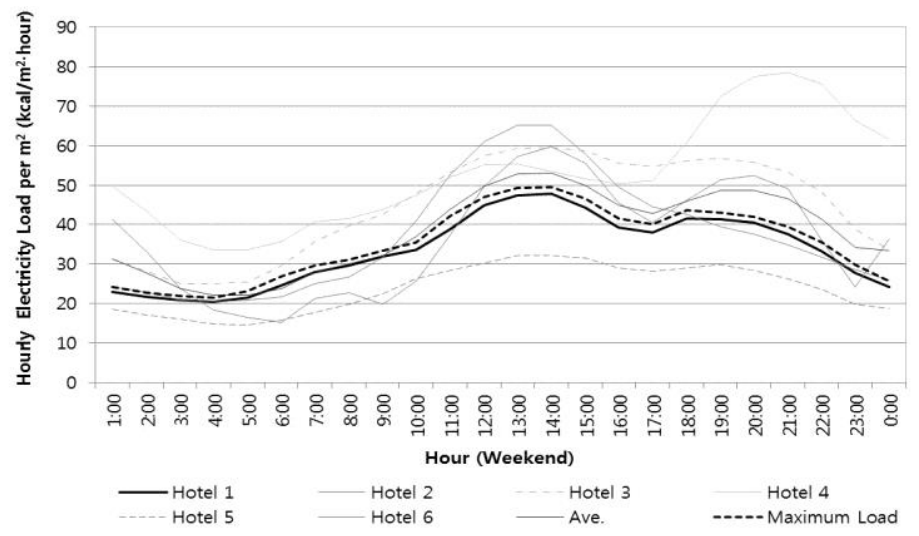

Figure 8. Weekend Hourly Electricity Load per $\mathbf{m}^{2}$

With recognition of the electricity load difference between weekdays and weekends based on the daily electricity load patterns per unit area of large-scale hotels, this researcher looked into hourly electricity load patterns on weekdays and weelend. The hourly electricity load per unit area on weekdays shows that the load graduall increased from 4:00 a.m. to about 3:00 p.m., and at about 8:00 p.m. the electricity load reached its peak. The living patterns on weekdays are mostly business and social activities. Therefore from early morning to 5-6 p.m., hotel guests took part in many activities. At hight after business hours, hotels were used mainly for banquets and lodging. The hourly electricity load per unit area on weekends shows that the load gradually increased from the morning to about 1:00 p.m., after which it decreased slightly. After that, at 6.00 p.m., a great deal of load occurred. Weekend hotel guests used subsidiary facilities to participate in banquets, weddings, and parties more than weekday hotel guests. Therefore, much of the electricity load occurred from late morning to nighttime. Hotels are used primarily for business on weekdays and for banquets and rest on weekends. Therefore, the use purposes on weekdays are different from those on weekends. Further, the characteristics of hotel guests vary depending on their purposes, and the use time of each facility is also different As a result, the hourly electricity load pattern is different from the maximum load depending on the time zone. There is also a difference in overall electricity load.

\section{Analysis of Electricity Peak Load of Large Hotels in the Context of Energy Efficiency, and Preparation of a Peak Load Profile}

\subsection{Analysis of the Properties of the Electricity Peak Load Profiles of Hotels}

To analyze the peak load properties of the hotels investigated in this study, days were divided into two types - peak days and ordinary days - and each hourly electricity load per unit area on peak days and on ordinary days was investigated. Each electricity load of the hotels on peak days and ordinary days appeared to be similar. There were two occurrences of peak load in the daily unit. However, each hourly electricity load on peak days and ordinary days was clearly different.

As shown in Figure 9, on peak days, a small peak load occurred at around 7:00 a.m., and the highest peak load occurred at 1:00 p.m. The second peak load occurred at 7:00 p.m. On ordinary days, electricity load was highest at 1:00 p.m. However, the maximum electricity load occurred at around 6:00-7:00 p.m. Among the many factors affecting electricity load demand, outdoor temperature was considered in this study. Outdoor temperature on peak days 
was lower than the monthly average temperature in the winter and higher than that in the summer. It should be recognized that the daily load pattern on peak days was different from the universal daily load pattern. Management of stable electricity demand and operation of stable building energy should be achieved.

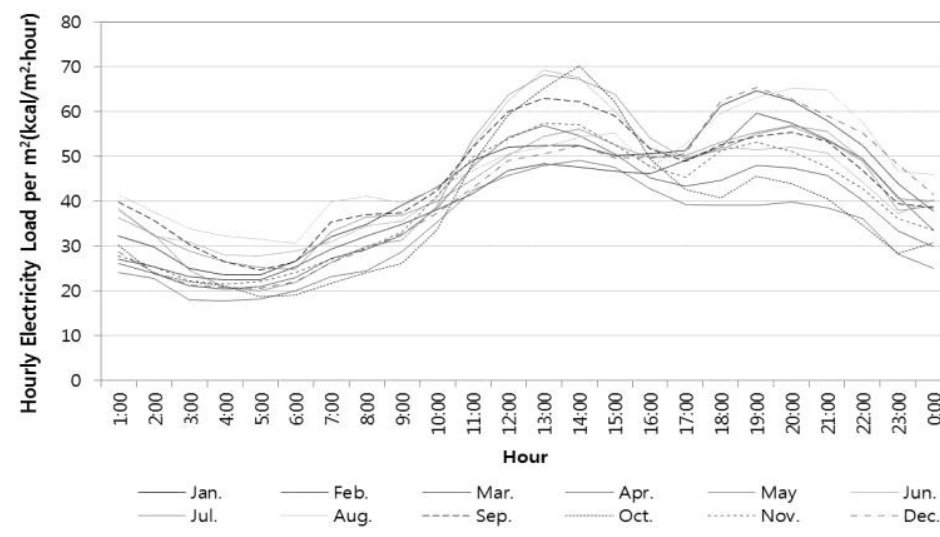

Figure 9. Peak Day Hourly Electricity Load per m²

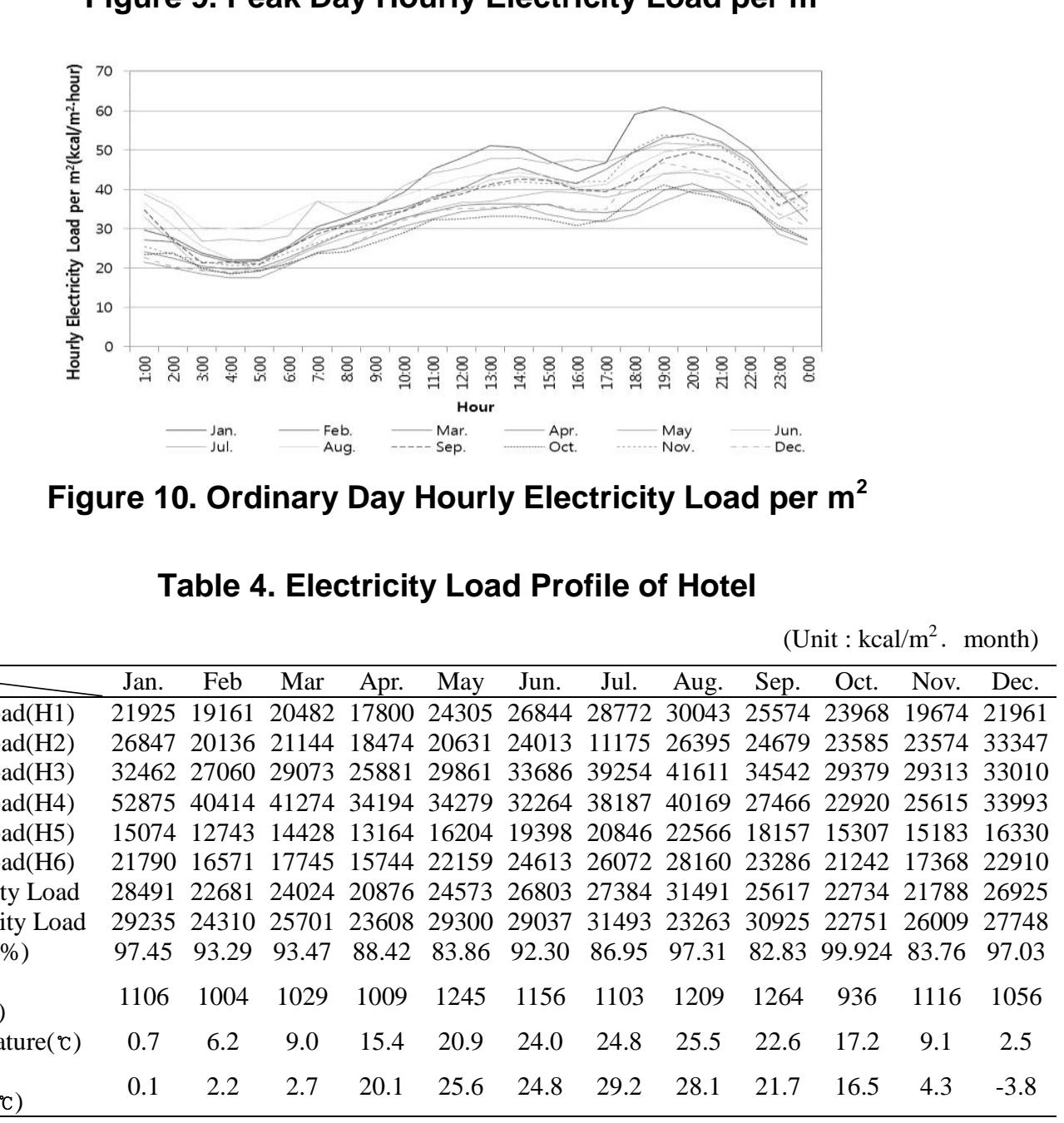

Electricity Load( $(\mathrm{H} 1)$

Electricity Load( $\mathrm{H} 2)$

Electricity Load(H3)

Electricity Load(H4)

Electricity Load(H5)

Electricity Load(H6)

Ave. Electricity Load

Max. Electricity Load

Load Factor $(\%)$

Peak Load

(kcal/ $/ \mathrm{m}^{2}$. day)

Ave. Temperature $\left({ }^{\circ} \mathrm{C}\right)$

Peak day

Temperature $\left({ }^{\circ} \mathrm{C}\right)$

$21925191612048217800243052684428772 \quad 3004325574239681967421961$

$\begin{array}{llllllllllll}26847 & 20136 & 21144 & 18474 & 20631 & 24013 & 11175 & 26395 & 24679 & 23585 & 23574 & 33347\end{array}$

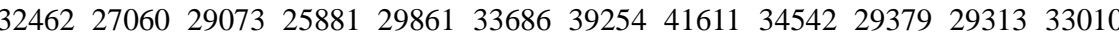

$\begin{array}{lllllllllllll}52875 & 40414 & 41274 & 34194 & 34279 & 32264 & 38187 & 40169 & 27466 & 22920 & 25615 & 33993\end{array}$

$\begin{array}{lllllllllllll} & 15183 & 16330\end{array}$

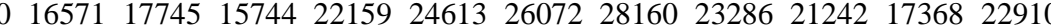

$\begin{array}{llllllllllll}0.7 & 6.2 & 9.0 & 15.4 & 20.9 & 24.0 & 24.8 & 25.5 & 22.6 & 17.2 & 9.1 & 2.5\end{array}$

$\begin{array}{llllllllllll}0.1 & 2.2 & 2.7 & 20.1 & 25.6 & 24.8 & 29.2 & 28.1 & 21.7 & 16.5 & 4.3 & -3.8\end{array}$ 
A massive amount of electricity load occurs constantly because of the large scale of hotels, the interior lighting, and an increase in electricity demand. Under the circumstances, it is important to reduce the entire energy consumption of buildings. It is even more important to prevent a national blackout by reducing peak load. A prerequisite for understanding the electricity consumption of hotels is to investigate their electricity load profile. Table 4 presents the electricity load profile of each hotel in this study. Load rate was calculated by dividing the monthly average electricity load by the maximum electricity load of a particular month.

To investigate the peak demand occurrence frequency of the hotels, hourly electricity load was enumerated from the highest load to the lowest load. Figure 11 illustrates this enumeration. Peak load occurs over a very short period of time. When average electricity load and maximum electricity load are compared, the difference is $79.67 \%$ on average. All types of load except for peak load show a linear pattern and are predictable. However, in is hard to predict the electricity demand peak that occurs in a short time but requires a lot-of electricity. To find a way to reduce peak load and supply stable electricity based on demand, it is necessary to remove peak demand. Further, it is necessary to level off a loadcurve by moving the peak load to a different time zone.

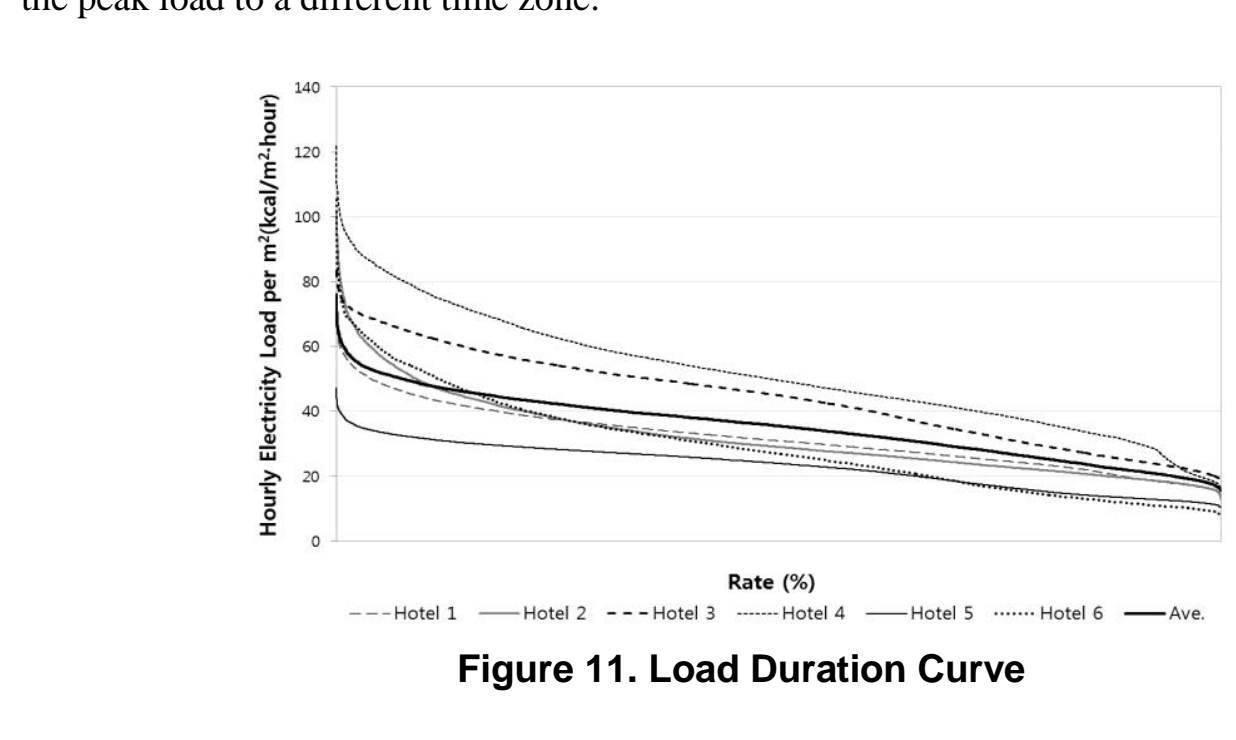

\subsection{Classification of the Hotels in Accordance with the Building Energy Efficiency Rating System}

In this study, the load data on the primary energy consumption of hotels were used. The data were applied to the building energy efficiency rating system. To calibrate the consumption energy by building use from the primary energy consumption of each hotel, a calculation was performed that reflected a calibration coefficient based on accommodation use and a regional coefficient including regional weather conditions. Investigation of the corelation between peak load and building energy efficiency is based on the building energy efficiency rating system. The hotels were classified into six discretionary grades (I, II, III, IV, $\mathrm{V}$, and VI).

This study is not intended to accurately rate the efficiency grade of each hotel in accordance with the domestic building energy efficiency rating system, but is intended to analyze the correlations between the efficiency grades and peak load in accordance with a certain criterion. Therefore, the hotels were divided into the following grades: I, II, III, IV, V, and VI. Although the hotels are large-scale buildings located in the same region and the same 
climate, they can be classified into various efficiency grades, depending on whether they are 1 st or 2 nd rate hotels, as well as gross floor area, construction year, facilities, and airconditioning schedule.

In this study, an analysis was performed on electricity peak load on the basis of the relative building energy efficiency grades of the hotels drawn from the same criteria, and their correlations were explored.

Table 5. Classification of Energy Efficiency Rating System

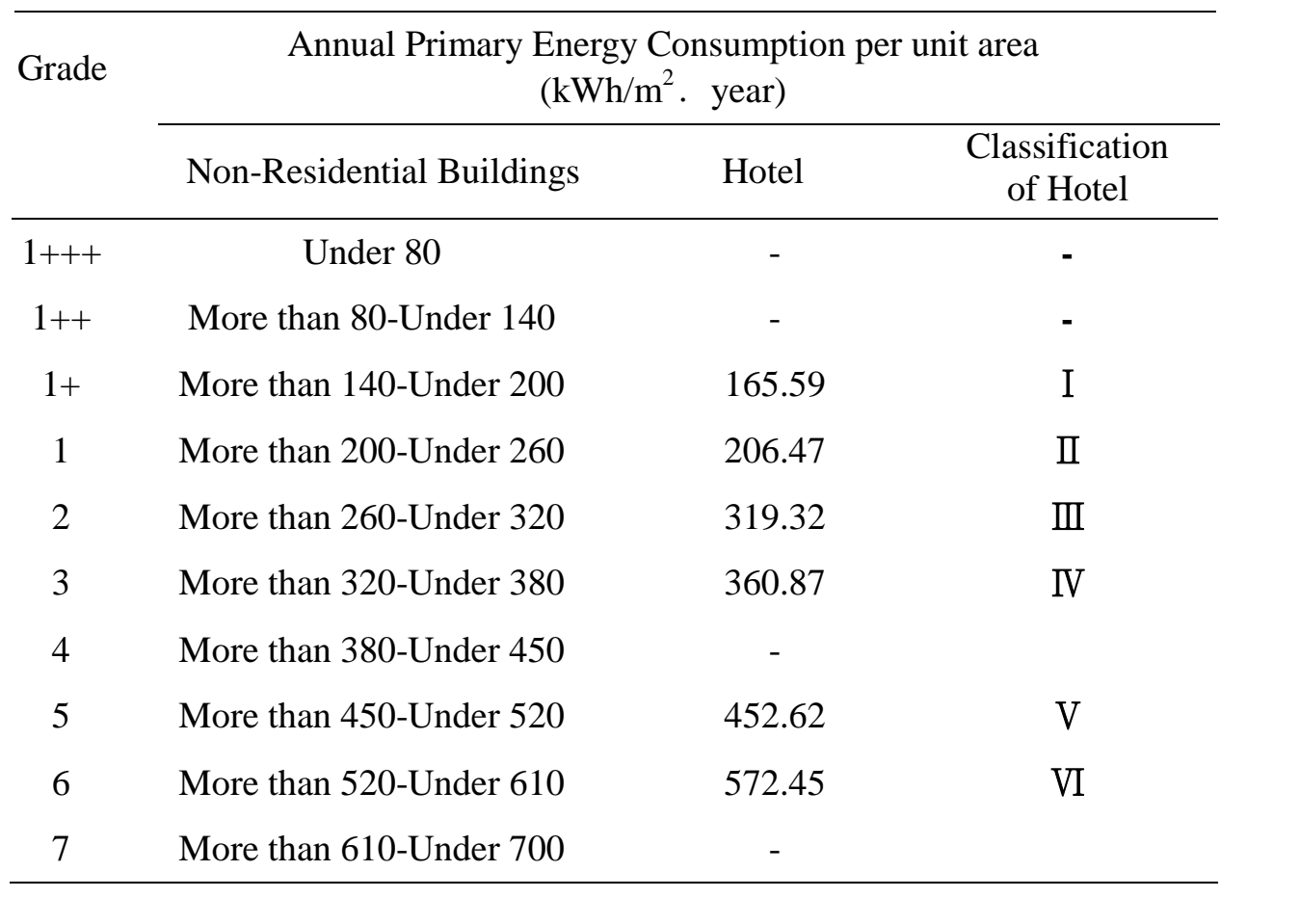

4.3. A Correlation Analysis on the Peak Load of Large Hotels in the Context of Energy Efficiency

Large-scale hotels that are in use 24 hours a day, 365 days a year, are high energyconsuming buildings. However, they have limitation factors that become obstacles to reducing energy such as high facility investment cost, comfort requirements, guest satisfaction, and low management priority.

As a way of determining the price of a hotel guestroom based on demand, a peak load pricing theory is applied. This theory is a determining method based on the peak load for the room, aking into account the demand for efficient pricing changes. As such, large hotels have a close relationship with peak load occurrence based on energy consumption. Therefore, to prepare a plan to reduce peak load, it is necessary to understand the properties of peak load and relevant factors in advance.

To define the relationship between building energy efficiency and peak load through correlation analysis, this study visualized statistically the effects of the hotel's energy efficiency grades on peak load occurrence frequency, the entire average electricity load, and electricity peak load. Table 6 presents the correlation analysis Pearson $\mathrm{R}$ value of each peak load by factors based on building energy efficiency rating. 
Table 6. The Correlation Analysis Pearson R Value

\begin{tabular}{lccc}
\hline & Frequency & Ave. Load & Peak Load \\
\hline Pearson R & 0.927 & 0.855 & 0.701 \\
\hline
\end{tabular}

At peak hour, that is, the time of day when the biggest load occurs in the winter and summer, peak-cut is sometimes necessary. In the case, the off-peak time that is used for reducing peak demand distribution and peak load occurrence frequency is an alternative in terms of electricity supply. Therefore, this study examined the electricity peak load occurrence frequency on the basis of building energy efficiency. The correlation analysis result revealed that the Pearson $\mathrm{R}$ value (a number that represents the degree of the correlation between variables $\mathrm{X}$ and $\mathrm{Y}$ ) was 0.927 , which indicates a clearly quantitative linear relation. Therefore, it is concluded that the peak load occurrence frequency can be reduced by improving building energy efficiency.

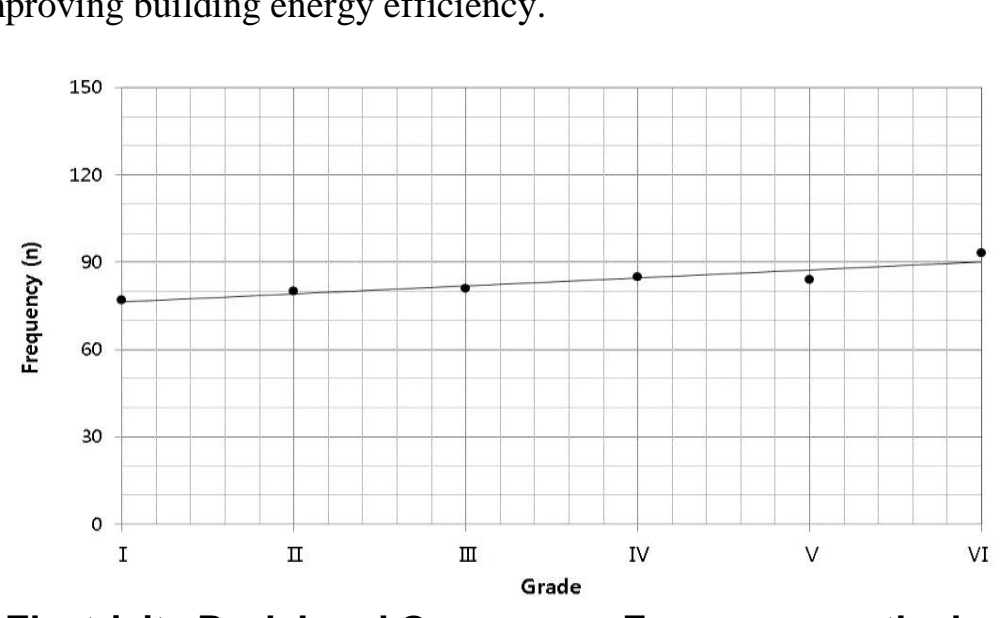

Figure 12. Electricity Peak Load Occurrence Frequency on the basis of Hotel

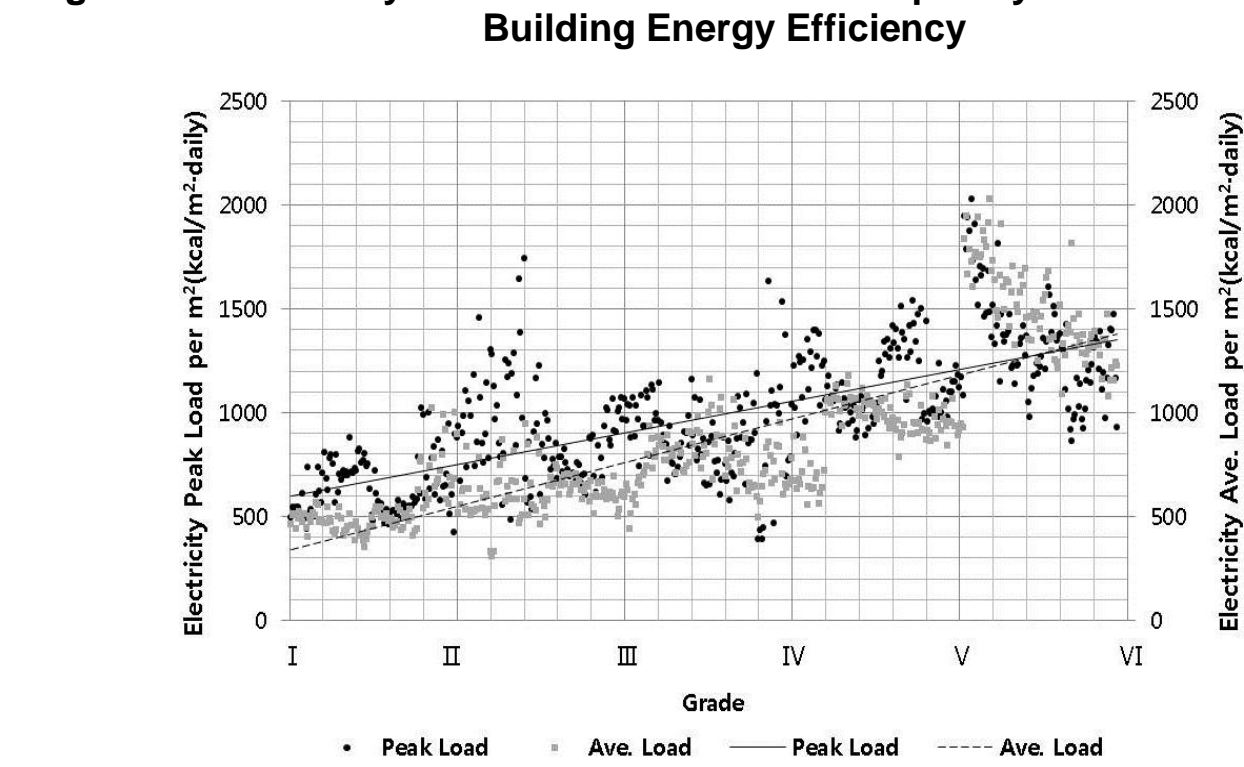

Figure 13. A Correlations Between the Energy Efficiency Grade, Average Electricity Load, and Electricity Peak Load 
Figure 13 illustrates the correlations between the energy efficiency grade, the average electricity load, and the electricity peak load of the hotels.

The Pearson $R$ value of the average electricity load on the basis of the energy efficiency grade of the hotels was 0.855 , and the Pearson $R$ value of the electricity peak load was 0.701 , thus there was a statistical significance. This shows that the two variables have a significant relationship in the positive direction. In other words, the higher the building energy efficiency grade of hotels located in the same region and the same climate, the lower are both the average electricity load and the electricity peak load per unit area.

If the study hotels that were rated relatively low VI grade are improved to grade I in terms of the building energy efficiency rating, it would be possible to reduce the electricity peak load by about $34.54 \%$ from the current peak load, and for the average electricity load to be reduced by about $52.56 \%$. That is, if the annual average electricity load is reduced by $10 \%$, it would be possible to reduce the electricity peak load by $6.57 \%$.

The study is intended to analyze the possibility of reducing the entire electricity load and electricity peak load through an improvement in the energy efficiency of hotels that are typical high energy consuming buildings, and to propose a plan to reduce electricity peak load through a decrease in the entire electricity load.

Investigating electricity load is a prerequisite for technicatly and economically evaluating the energy management of buildings and finding alternatives. From the standpoint of national energy and security, it is also necessary to manage and predict the electricity peak load of high energy consuming buildings.

Further, the nation's reserve electricity security and electricity supply is expected to be strengthened through an improvement in energy efficiercy of buildings that account for more than $20 \%$ of the national energy consumption.

\section{Conclusion}

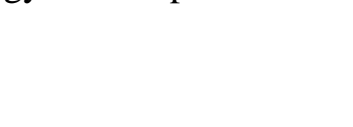

In this study, an investigation was performed on the properties of electricity peak load of large-scale hotels located in 0 legu, Korea, that have a typically high energy consumption per unit area and a massive amount of load. The investigation was done on the basis of building energy efficiency.

In this study the electricity load data of the hotels were used to analyze the properties of electricity load, and the correlations between building energy efficiency rating and electricity peak load. The results of the analysis on the peak load properties of large hotels in the context of energy efficiency arepresented as follows:

First, this study divided days into peak days and ordinary days in order to examine the hourly electricity load per unit area. The results showed clear differences in hourly load pattern and peak hour.

Second to define the relationship between building energy efficiency and peak load through the correlation analysis, this study statistically visualized the effects of the hotels' energy effliciency grades on peak load occurrence frequency.

As a result, the Pearson $\mathrm{R}$ value was 0.927 , which means that there was a clearly quantitative linear relationship. Therefore, it is concluded that an improvement in building energy efficiency can lead to a decrease in peak load occurrence frequency.

Third, the Pearson R value of average electricity load on the basis of the hotels' energy efficiency was 0.855 , and the Pearson $\mathrm{R}$ value of the electricity peak load was 0.701 , thus there was a statistical significance. This shows that the two variables have a significant relationship in the positive direction. In other words, the higher the building energy efficiency grade of the hotels located in the same region and the same climate, the lower are both the average electricity load and the electricity peak load per unit area. Therefore, it is concluded 
that it is possible to reduce peak load and average load by improving building energy efficiency.

The study is intended to analyze the possibility of reducing the entire electricity load and electricity peak load through an improvement in the energy efficiency of hotels buildings that are typical high energy consuming buildings, and to propose a plan to reduce electricity peak load through a decrease in the entire electricity load.

It is very important to understand the peak load properties of the building unit energy. The proposed data and properties analysis of the results in this study are aimed at reducing the electricity peak load and overload pattern of hotels and other types of buildings, and they can be used as fundamental materials to improve building energy efficiency.

If building energy is efficiently managed, it is possible to reduce peak load, secure reserve electricity without additional investment in facilities, expand power generation, transmission, and distribution, prevent unnecessary investment into power systems, and reduce SOC cost.

Currently, there is no a specific criteria for the peak load of buildings. To achieve the goals of national energy efficiency and demand management policy, it is necessary to introduce the peak demand rating or peak demand performance evaluation on the basis of the average peak load of each building group.

\section{Acknowledgements}

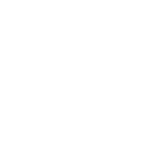

This work was supported by the National Research Foundation of Korea(NRF) grant funded by the Korea government(MSIP) (NRF-2013R1A2A1A01014020).

\section{References}

[1] K. S. Bang, "Real Estate Terms Dictionary", Buyeunsa, Korea, (2011).

[2] J. H. Han, "Exploiting the Flexibility of Controllable Residential Loads for Energy and Peak Demand Savings", MA thesis, Yonsei University, Korea, (2012).

[3] W. H. Hong, J. Y. Kim, C. M. Lee and G. Y. Jeon, Energy Consumption and the Power Saving Potential of a University in Korea: Using Feild Survey', J. Asian Architecture and Building Engineering, vol. 10, no. 2, (2011).

[4] J. W. Jeon, "Analytical Study on the Saving of Cooling and Heating Load in the Hotel Guest Rooms", MA thesis, Korea University, Korea, (2005)

[5] Korea Energy Economics Institute, Energy Consumption Survey 2011, Korea Knowledge Economy Corporation, (2012).

[6] H. N. Lee, Eleetricity Peak Equation: Estimation and Prediction", Korean Energy Economic Review, vol. 9, no. 2, (2010).

[7] K. K. Lee, S. B. Km and W. H. Hong, "Sensitivity to electricity consumption in urban business and commercial area buildings according to climatic change", J. J.Cent, South Univ, vol. 19, (2012).

[8] Ministry of Land and Infrastructure and Transport, Building Energy Efficiency Rating System (Amendment). Korea Knowledge Economy Corporation, (2013).

[9] I. A. T. Nabeel, "Daily load profile and monthly power peaks evaluation of the urban substation of the capital of Jordan Amman”, J. Electrical Power and Energy System, vol. 37, no. 1, (2012).

[10] R. S. Patricia, V. R. B. Silva and F. G. Jota, "Building load management using cluster and statistical analyses", J. Electrical Power and Energy Systems, vol. 33, no. 8, (2011).

[11] C. H. Pyo, "A study on the efficient operations of electric equipments in the hotel", MA thesis, Hanyang University, Korea, (2007).

[12] J. H. Ryu, Y. K. Seo, I. C. Shim, W. H. Hong and K. W. Kim, "A Study on City Gas Consumption Characteristics and Correlation Factor Analysis for Special Grade Hotels Located in Daegu", J. architectural institute of Korea, vol. 28, no. 10, (2012).

[13] B. H. Sohn, J. Y. Kim and W. H. Hong, "A Study on the Typical Energy Consumption Value of the Hotel in Daegu", architectural institute of Korea, vol. 25, no. 1, (2005).

[14] C. William and Y. V. Hui, "A study of energy efficiency of private office buildings in Hong Kong”, J. Energy and Buildings, vol. 41, no. 6, (2009). 
[15] J. H. Ryu, W. H. Hong and Y. K. Seo, "A Study of the Analysis on the Properties of Electricity Peak Load of Large Hotel Buildings in Consideration of Energy Efficiency", Advanced Science and Technology Letters (Architecture and Civil Engineering 2014), vol. 47, (2014).

\section{Author}

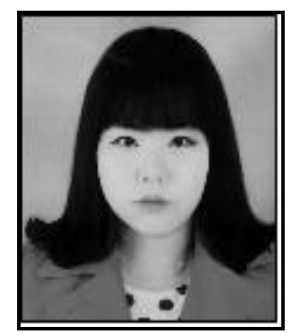

\section{Ji-Hye, Ryu}

Ph.D Student

School of Architectural, Civil, Environmental and Energy Eng., Kyungpook National University, Daegu, Korea

ryou0407@knu.ac.kr

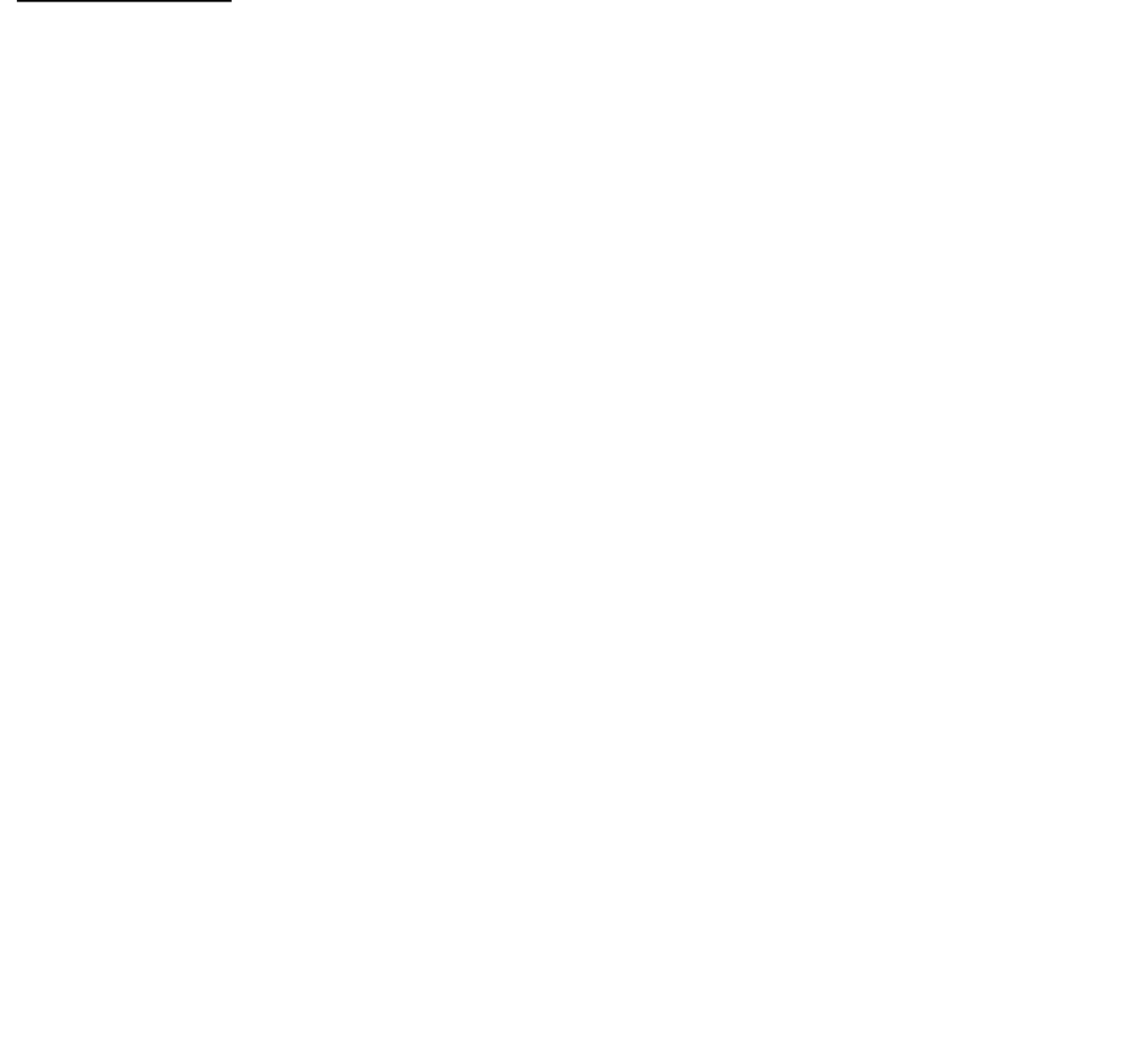


International Journal of Smart Home

Vol.8, No.3 (2014)

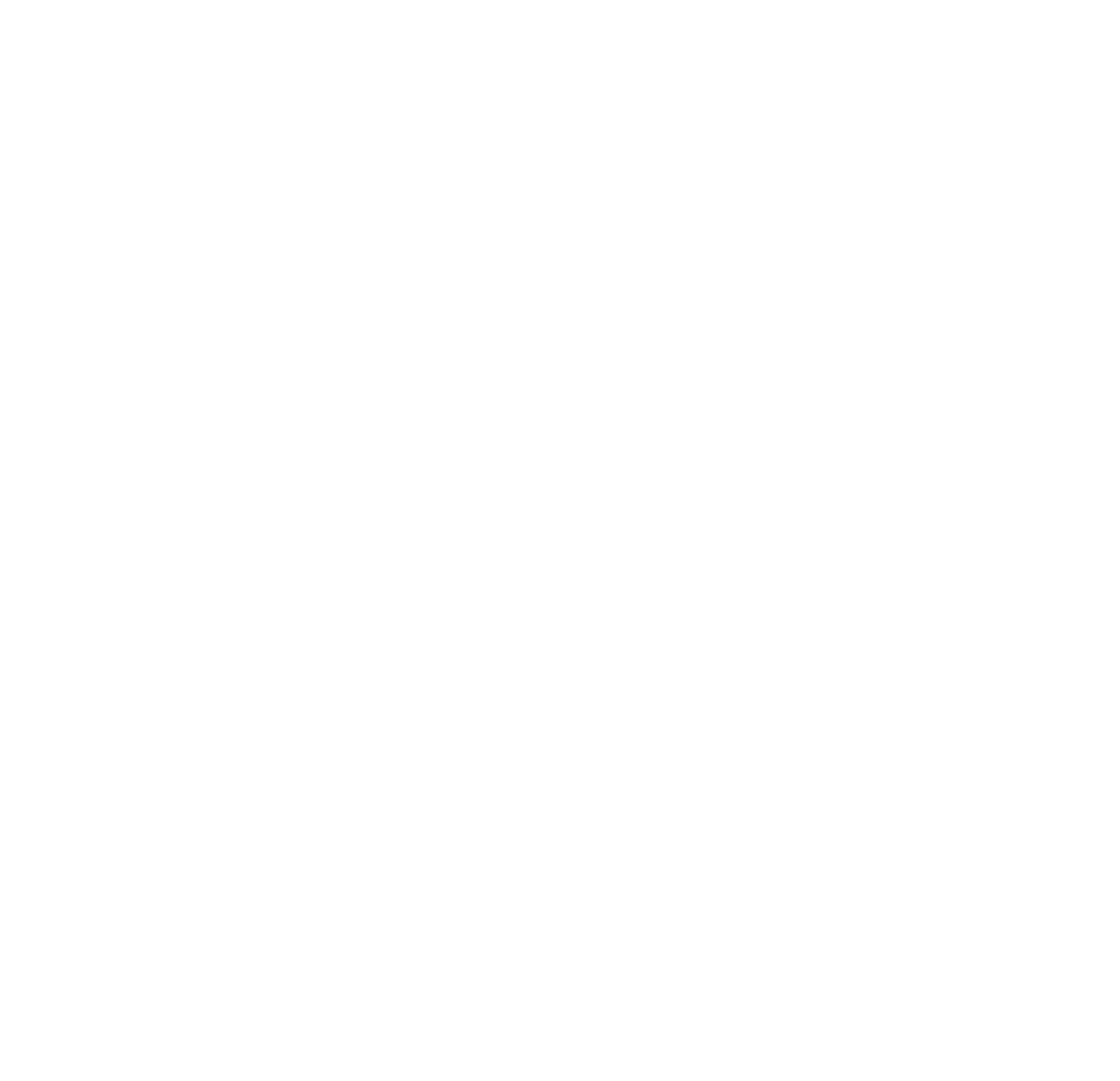

